REVISIÓN

\title{
Necesidades proteicas de los deportistas y pautas diétetico-nutricionales para la ganancia de masa muscular
}

\author{
Aritz Urdampilleta ${ }^{a, b *}$, Néstor Vicente-Salar ${ }^{c}$ y J osé Miguel Martínez Sanz ${ }^{d}$ \\ a Departamento de Farmacia y Ciencias de Ios Alimentos, Universidad del País Vasco, España \\ ${ }^{\text {b}}$ Departamento de Educación Física y Deportiva, Universidad del País Vasco, España \\ cInstituto de Bioingeniería, Universidad Miguel Hernández, Elche, Alicante, España \\ dPrograma de Tecnificación de Triatlón, Universidad de Alicante, Alicante, España
}

Recibido el 21 de abril de 2011; aceptado el 19 de septiembre de 2011

PALABRAS CLAVE
Músculos;
Hipertrofia;
Proteínas;
Deportes;
Ejercicio;
Suplemento dietético,
deporte;
Requerimientos
nutricionales

Resumen Uno de los efectos más importantes del entrenamiento de la fuerza es el aumento de la hipertrofia muscular. Para compensar sus limitaciones genéticas, los deportistas deben tratar de optimizar los recursos dietético-nutricionales. El objetivo de la presente revisión es analizar la evidencia científica del aporte proteico del deportista según las diferentes modalidades deportivas. Dependiendo del gasto y el aporte energéticos del deportista, el aporte total de proteínas de la ingesta energética diaria suele suponer un 10-15\% sin embargo, es preferible calcular la cantidad proteica necesaria por $\mathrm{kg}$ de peso corporal de cada individuo en concreto y según la disciplina deportiva. En este sentido, se estima que para mantener la masa muscular los deportistas deben consumir 1,2-1,8 g de proteínas/ kg/ día, y para aumentarla (0,5 kg masa muscular/ semana) deben mantener una ingesta proteica de 1,6-1,8 g de proteína/ kg/ día, con un aumento de 400$500 \mathrm{kcal}$ en su dieta habitual, entendiendo que estas necesidades variarán según la modalidad deportiva, la destrucción muscular generada, la masa muscular del atleta y los depósitos de glucógeno. Es importante señalar que los depósitos de glucógeno muscular y hepático vacíos aumentarían las necesidades proteicas para mantener la masa muscular. Un exceso de ingesta de proteínas (>2 g/ kg/ día) con las reservas de glucógeno agotadas podría causar un aumento de la concentración de cuerpos cetónicos y urea, y producir, entre otros, deshidratación precoz del deportista.

(c) 2011 Asociación Española de Dietistas-Nutricionistas. Publicado por Elsevier España, S. L. Todos los derechos reservados.

\footnotetext{
*Autor para correspondencia.

Correo electrónico: aritzurdampi@hotmail.com (A. Urdampilleta).
} 


KEYWORDS
Muscles;
Hypertrophy;
Proteins;
Sports;
Exercise;
Dietary supplement,
sport;
Nutritional
requirements

\section{Protein needs in athletes and dietary-nutrition guidelines to gain muscle mass}

Abstract One of the most important effects of strength training is muscular hypertrophy. Athletes should optimize their nutritional management in order to compensate their own genetic limitations. The aim of this review is to analyze the scientific evidence concerning protein intake as a tool to achieve muscle hypertrophy. Depending on the expenditure and energy intake of athlete, a daily protein ranging between $10-15 \%$ of total dietary intake is needed. However in sports diets, it is preferable to estimate the amount of protein needed per kilogram of body weight in each individual. In this regard athletes should ingest an amount between $1.2 \mathrm{~g}$ and $1.8 \mathrm{~g}$ of proteins/ $\mathrm{kg}$ of body mass/ day to maintain their lean mass. In order to increase muscle mass ( $0.5 \mathrm{~kg} /$ week), athletes should take between $1.6 \mathrm{~g}$ and $1.8 \mathrm{~g}$ of protein/ $\mathrm{kg} /$ day with an increase of $400-500 \mathrm{kcal}$ in their daily diet. These needs will depend on the sport, muscular catabolic status, the athlete's lean mass and glycogen stores. Protein needs will increase if muscle and liver glycogen stores are empty. Excess of protein intake (more than $2 \mathrm{~g} / \mathrm{kg} /$ day), with full glycogen stores, does not benefit the athlete and could cause an increase in circulating ketones and urea, thereby producing an early dehydration.

๑ 2011 Asociación Española de Dietistas-Nutricionistas. Published by Elsevier España, S. L. All rights reserved.

\section{Metabolismo proteico y ejercicio físico}

Las proteínas son para los seres humanos uno de los macronutrientes esenciales que desempeñan una amplia variedad de funciones fisiológicas importantes: forman la base estructural del tejido muscular, son el principal componente de la mayoría de las enzimas musculares, son la base del sistema inmunitario y tienen un papel destacado en el rendimiento físico.

Hay diversos parámetros y técnicas para estudiar el metabolismo de las proteínas durante el ej ercicio. Por una parte, se puede utilizar la determinación de la concentración de la urea, un producto intermedio del metabolismo de las proteínas que se encuentra en orina, sangre o sudor. Por otra parte, se puede utilizar el aminoácido (AA) modificado 3-metilhistidina que se encuentra en la orina para evaluar el catabolismo de las proteínas. En un individuo el nitrógeno aportado por la dieta debe mantener un equilibrio con el excretado en orina, heces y sudor, por lo tanto, el análisis del balance nitrogenado es una alternativa útil para evaluar el estado proteico. Por último, existen estudios experimentales de trazabilidad mediante la ingesta de aminoácidos marcados con isótopos radiactivos que permiten determinar su función metabólica durante el ejercicio ${ }^{1}$. Pese a la precisión de dichos estudios, no se suele utilizarlos frecuentemente debido a sus grandes inconvenientes al ser procesos invasivos, potencialmente peligrosos por la utilización de isótopos, y con un coste económico alto².

En general, no se considera a las proteínas como una importante fuente energética durante la actividad física, ya que los hidratos de carbono (HC) y las grasas desempeñan principalmente esta función. No obstante, debemos tener en cuenta que las reservas de energía inmediatas suelen estar compuestas por los depósitos de glucógeno muscular y hepático, los cuales pueden tener un peso total de aproximadamente $400-500 \mathrm{~g}$ (cuyo aporte energético es de 1.600$2.000 \mathrm{kcal}$, aproximadamente), y por la grasa intramuscular y que, por lo tanto, en deportes de resistencia de larga duración, las proteínas pueden ser un importante recurso energétic $0^{3,4}$.

En la mayoría de los ejercicios, entre ellos el entrenamiento extenuante de levantamiento de pesas, las proteínas aparecen como un recurso energético limitado que aporta menos del $5 \%$ del gasto energético total. Las proteínas pueden utilizarse para producir cantidades significativas de ATP en el músculo, pero su velocidad de producción es mucho más lenta que la de los $\mathrm{HC}^{5}$. En los deportes intensos de fuerza-resistencia, la necesidad energética proteica es muy baja, al utilizarse en gran medida el glucógeno muscular. En consecuencia, las dietas ricas en proteínas no son recomendables para la mayoría de los atletas, ya que no ayudan a reponer los depósitos de glucógeno muscular ${ }^{6,7}$. No obstante, estudios recientes indican que un aumento proteico en la bebida de reposición tras el ejercicio aumenta los depósitos de glucógeno muscular en mayor medida que si se toma sólo $\mathrm{HC}^{8,9}$.

Los AA pueden ser de gran utilidad como recurso energético en los deportes de larga duración, especialmente en las últimas fases del ejercicio, donde son frecuentes los cambios de ritmo; pueden utilizarse como fuente energética hasta en un $10-15 \%$ Se ha observado que el catabolismo proteico aumenta significativamente cuando se ha agotado un $33-55 \%$ de los depósitos de glucógeno muscular y se acompaña de ejercicio intenso con múltiples microtraumatismos generados por el impacto de la pisada contra el pavimento ${ }^{4}$.

Algunos trabajos publicados señalan que el ejercicio hasta el agotamiento activa una serie de enzimas que inducen la proteólisis ${ }^{10-13}$. De esta forma, Ios AA liberados por dicho proceso pueden entrar en las vías energéticas, como es el caso de la leucina ${ }^{13}$, que produce cuerpos cetónicos. Los productos intermediarios de la valina y la isoleucina acaban combinándose con el piruvato en la célula muscular para convertirse en alanina y su alfacetoácido. A su vez, la alani- 

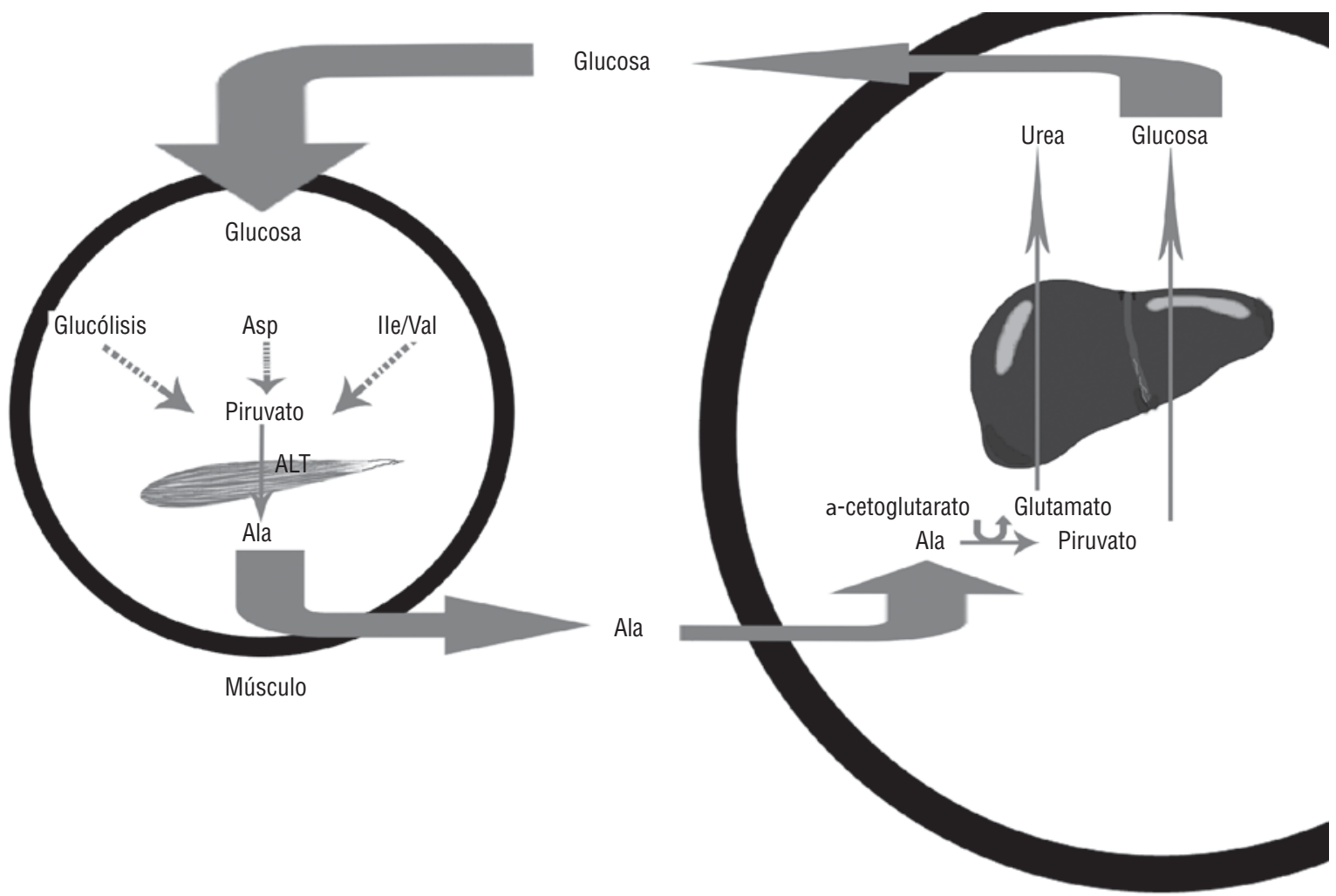

Hígado

Figura 1 Ciclo de la glucosa-alanina. Ala: alanina; ALT: alanina aminotransferasa; Asp: aspartato; lle: isoleucina; Val: valina. La alanina es producida en el tejido muscular a partir de la degradación de aminoácidos. A continuación, la alanina es liberada a la sangre y transportada al hígado para su posterior conversión en glucosa mediante el proceso de gluconeogénesis. Fuente: elaboración propia.

na es liberada al torrente sanguíneo y, ya en el hígado, se convierte en glucosa mediante la gluconeogénesis, así se cierra el denominado ciclo de la glucosa-alanina ${ }^{12}$. Asimismo, la alanina podría actuar como un medio de transporte de grupos nitrogenados para la producción de urea en el hígado, tal y como muestra la figura 1.

Diversos estudios demuestran que, durante la última fase de ej ercicio de larga duración, las concentraciones sanguíneas de alanina tienden a elevarse, debido probablemente a procesos proteolíticos en el tejido muscular $4,11,14$. La producción estimada de glucosa mediante el ciclo de la glucosa-alanina es baja, ya que se producen solamente $4 \mathrm{~g}$ de glucosa/h. Dicha obtención de energía es escasa, en comparación con la glucólisis anaeróbica, que tiene una capacidad de liberación de glucosa de 3 g por minuto ${ }^{14}$

Cabe mencionar también la utilización energética de los AA ramificados procedentes del hígado, especialmente durante el ejercicio de resistencia de larga duración, cuando los valores de glucógeno muscular están reducidos, ya que pueden proporcionar energía directamente al músculo a través de la glucosa producida a partir de ellos. Una dieta baja en HC y alta en grasas y proteínas o cetogénica facilitaría este proceso, ya que de este modo los AA podrían emplearse durante el ej ercicio para proporcionar energía.

No obstante, una ingesta alta en $\mathrm{HC}$ antes, durante y después del ejercicio prolongado, principalmente si el ejerci- cio es traumático, permitiría reducir el uso de las proteínas del organismo para la obtención de energía. Esto se debe a que una concentración adecuada de glucógeno muscular parece inhibir las enzimas del catabolismo proteico muscu$\operatorname{lar}^{2}$ producido mayoritariamente por el cortisol9,15. Este efecto podría ser producido por la insulina, una de las hormonas más anabólicas del organismo, cuya secreción depende de los HC de la dieta ${ }^{16}$. Reducciones energéticas drásticas a costa de los hidratos de carbono, manteniendo una alta ingesta de proteínas, pueden afectar a las concentraciones de insulina, además de disminuir las hormonas anabólicas IGF-1 y la testosterona, como ocurre a los culturistas que se preparan semanas antes para competir ${ }^{17}$.

Las evidencias disponibles apuntan a que el metabolismo de las proteínas y los AA como recurso energético en ciertas situaciones puede incrementarse y llegar hasta un $15 \%$ de la utilización energética ${ }^{4}$. No obstante, la magnitud de su contribución depende de varios factores, como la intensidad del ejercicio, su duración, el carácter del esfuerzo y la disponibilidad de otras fuentes de energía como el glucógeno muscular almacenado.

Por una parte, hay autores que han remarcado que un aumento en la ingesta de proteínas mediante suplementación (30 g/ día) puede producir un aumento de síntesis proteica, tanto en adolescentes como en ancianos que entrenan la fuerza ${ }^{18,19}$. Por otra parte, los ancianos que no toman 
suficiente cantidad de proteínas (menos de $0,8 \mathrm{~g} / \mathrm{kg}$ de peso corporal) pierden masa muscular rápidamente ${ }^{18}$, hecho que pone de manifiesto la importancia del aumento de la ingesta proteica en colectivos ancianos que realizan actividad física.

Ante la cuestión de la necesidad de un aporte mayor de proteínas en individuos deportistas, o cuál es la fuente proteica ideal, la presente revisión intenta ofrecer la mayor información contrastada para que puedan utilizarla como herramienta dietético-nutricional los profesionales que están implicados en el asesoramiento de este colectivo.

\section{Cuerpo: necesidades proteicas de los deportistas}

Sin lugar a dudas, determinar la cantidad adecuada de proteínas y AA esenciales en la dieta es de gran importancia para el colectivo de deportistas en diferentes estados fisiológicos, ya que un déficit proteico produce una disminución en la capacidad de generar la máxima potencia muscu$\operatorname{lar}^{3,20}$.

Algunos estudios afirman que una cantidad adicional del contenido proteico en la dieta en forma de suplementos de AA 0 aislados de proteínas es necesaria para conseguir un rendimiento óptimo ${ }^{21-24}$. Del mismo modo que la ingesta de $\mathrm{HC}$ tras el ejercicio es necesaria para acelerar los procesos de recuperación ${ }^{25,26}$, en ejercicios excéntricos donde se produce un mayor daño muscular la recuperación mejora cuando se aumenta la ingesta proteica inmediatamente después del ejercicio ${ }^{27-29}$, ya que se dan las óptimas condiciones hormonales para ell $0^{15,30}$

En un estudio basado en una dieta hipocalórica, con un porcentaje de $\mathrm{HC}$ bajo $(45-50 \%)$ y con un leve aumento de la ingesta proteica (13-20\%), se observó un aumento del rendimiento deportivo en atletas femeninas ${ }^{31}$. Asimismo, en otros trabajos se señala que la adición de una ligera cantidad de proteína a las bebidas de reposición con concentra- ciones de un $6 \%$ de $\mathrm{HC}$ aumenta el rendimiento deportivo aun disminuyendo ligeramente la cantidad de HC de la ingesta diaria ${ }^{32}$.

Las necesidades mínimas recomendadas de proteínas para los deportistas varían según el carácter del esfuerzo ${ }^{33}$. Dichas recomendaciones se resumen en la tabla 12,4,14,16,21,33-51. El valor inferior del intervalo asegura una ingesta adecuada en caso de entrenamientos con grandes volúmenes de trabajo y en estación invernal, periodo en el que el sistema inmunitario se encuentra más comprometido frente a los procesos gripales ${ }^{52,53}$.

Los deportistas que compiten en categorías por peso o simplemente deseen disminuir su peso corporal deben aumentar la cantidad de proteína diaria en torno a 1,4-1,8 g/ $\mathrm{kg}$ de peso corporal debido a que siguen dietas hipocalóri$\operatorname{cas}^{45,46}$ (tabla 1). Dicha estrategia contribuiría a evitar el catabolismo proteico muscular producido por la reducido concentración de glucógeno almacenado.

De esta forma, se puede decir que la composición de la dieta del deportista puede afectar a la respuesta al ejercicio bien de forma negativa (una ingesta inadecuada de $\mathrm{HC}$ que conduciría a un mayor agotamiento de las reservas de glucógeno hepático y muscular y, por lo tanto, una mayor utilización proteica) bien positiva: una alta ingesta de proteínas $(1,6-1,8 \mathrm{~g} / \mathrm{kg} /$ día) que puede promover un balance nitrogenado positivo que potencia la biosíntesis de proteínas ${ }^{42}$.

Como norma general, se ha consensuado que los deportistas que necesiten aumentar la masa muscular deben realizar una ingesta proteica de 1,6-1,8 g/ kg de peso corpo$\mathrm{ral}^{3,44}$. A su vez, los deportistas de resistencia que quieran mantener su masa muscular deberían ingerir 1,2-1,6 g de proteína/kg de peso corporal17,36; el límite superior es el idóneo para los individuos que entrenan la fuerza más la resistencia, algo muy habitual en la mayoría de los deportistas.

Se debe prestar especial atención a la hora de estimar la ingesta proteica a partir del porcentaje de la energía con-

Tabla 1 Ingestas recomendadas de proteínas ( $\mathrm{g} / \mathrm{kg}$ de peso corporal) para individuos sedentarios y físicamente activos

\begin{tabular}{|c|c|}
\hline Grupo & Cantidad de proteína necesaria para tener un balance positivo \\
\hline Sedentario & 0,8 (Etzel, 200437; Kerksick, 200833) \\
\hline Físicamente activos & $\begin{array}{l}\text { 1, 0-1,4 (Kreider y Campbell, 200977; Lemon, } 1996^{44} \text { y } 2000^{43} ; \text { Paul, } 1989^{47} ; \\
\text { Reeds y Hutchens, } 1994^{2} \text { ) }\end{array}$ \\
\hline Entrenamiento de fuerza*, mantenimiento & 1,2-1,4 (Grandj ean, 199339; Hicson, 199441; Kerksick, 200833; Wilians, 199351) \\
\hline Entrenamiento de fuerza & $\begin{array}{l}\text { 1,6-1, } 8 \text { (Lemon, 19924; Hickson y Wolinsky, 199441; Reeds y Hutchens, 19942; } \\
\text { Tipton, 200749) }\end{array}$ \\
\hline Ganancia de masa muscular* & $\begin{array}{l}\text { 1,7-1,8 + ingesta calórica positiva (400-500 kcal/ día, para ganar 0,5 kg de } \\
\text { musculo/ semana) (Bartels, 199234; Burd, 20093; Forbes, 199438; Koopman, } \\
\text { 200942; Symons, } 2007^{48} \text { ) }\end{array}$ \\
\hline Entrenamientos de resistencia & $\begin{array}{l}\text { 1,2-1,4 (Andersen, 2005²; Biolo, 199535; Chesley 1992 }{ }^{36} ; \text { Hoffman, } 2009^{54} \text {; } \\
\text { Hulmi, 200914; Lemon, 199644; Willoughby, 200716) }\end{array}$ \\
\hline Reducción de peso & $\begin{array}{l}\text { 1,4-1,8 (Hernandez, 199640; Nemet, 200546; Mettler, 201045; McCleave, } \\
\text { 201031) }\end{array}$ \\
\hline
\end{tabular}

*Se debe acompañar de los depósitos de glucógeno muscular elevados, ya que de lo contrario la ingesta proteica debería aumentar a 1,8-2 g de proteínas por kg de peso corporal (Koopman, 200942; Moore, 200995).

Tomada de Urdampilleta et al ${ }^{50}$ (2010). 
Tabla 2 Cálculo de proteínas según el peso corporal de un deportista de fuerza-resistencia (peso corporal, $70 \mathrm{~kg}$ )

\begin{tabular}{lcc}
\hline $\begin{array}{l}\text { Ingesta calórica diaria } \\
\text { (kcal/ día) }\end{array}$ & $3.500-4.000$ & $3.500-4.000$ \\
\hline Proteínas (\%) & 12 & 15 \\
Proteínas (kcal) & $420-480$ & $525-600$ \\
Proteínas (g) & $105-120$ & $131-150$ \\
Proteínas (g/ kg peso corporal) & $1,5-1,7$ & $1,9-2,1$ \\
\hline
\end{tabular}

sumida. A modo de ejemplo podemos afirmar que el contenido en proteínas de la dieta por término medio suele ser el $12-15 \%$ respecto a las necesidades calóricas diarias. A un individuo de $70 \mathrm{~kg}$, le corresponde una ingesta de 1,5-1,7 g de proteína por kg de peso corporal y día, tal y como se muestra en la tabla 2. Un incremento en el contenido proteico de hasta un $15 \%$ respecto a las necesidades calóricas diarias supondría unos valores de 1,9-2,1 g de proteína/ kg de peso corporal, cantidad que excede claramente sus requerimientos. Un $12 \%$ de proteínas, respecto a una ingesta de $3.500 \mathrm{kcal}$ diarias, cumple las necesidades proteicas mínimas para los deportistas de resistencia (tabla 1). No obstante, para los deportistas de fuerza o fuerza-resistencia se debería aumentar hasta un 13\% para alcanzar los requerimientos proteicos diarios que mantengan el estado anabólico en óptimas condiciones. Sin embargo, un 15\% de proteínas sería excesivo para dicho colectivo (tabla 2).

La mayor parte de los estudios que han analizado el balance de nitrógeno en colectivos deportivos señalan que la ingesta óptima de proteínas para alcanzar el máximo desarrollo muscular se sitúa en 1,7-1,8 g/ kg (alrededor del 225\% de la ingesta recomendada (IR) en personas sedentarias) ${ }^{3,54}$, y concluyen que cantidades superiores a $1,8 \mathrm{~g} / \mathrm{kg}$ de peso corporal no han demostrado tener mayor beneficio en el aumento de la masa muscular de los deportistas de fuerza ${ }^{55}$. En este sentido, los trabajos de Nicholas A. Burd ${ }^{3}$ y J ay R. Hoffman ${ }^{54}$ coinciden al concluir que, al consumir dietas que aportan más de $2,4 \mathrm{~g}$ de proteínas por kg de peso corporal, se aumenta la oxidación de AA sin que se observe un incremento adicional de biosíntesis proteica, aun con un entrenamiento adecuado de fuerza. Otros autores señalan también que no es necesario más de $2 \mathrm{~g}$ de proteínas por $\mathrm{kg}$ de peso corporal al día, ya que no presenta ningún beneficio frente a dietas con un contenido menor ${ }^{56-58}$

Pese a que las recomendaciones de ingesta de proteínas se suele dar por kg de peso corporal y día, se debe matizar que estas cantidades de proteínas deberían ser indicadas según la cantidad de masa muscular del individuo determinada peviamente ${ }^{59}$ mediante técnicas de análisis, como la tomografía computarizada (TC), o técnicas antropométricas. Por ej emplo, las necesidades proteicas para dos deportistas de fuerza de $90 \mathrm{~kg}$ de peso que difieran en sus porcentajes de masa muscular no deberían ser iguales, debido a que el individuo con un mayor porcentaje de masa muscular requerirá supuestamente de un mayor aporte de proteínas para mantener el estado anabólico que el de menor tejido muscular. Pese a que no se han encontrado muchos estudios que contemplen este aspecto, en dos estudios se concluye que la ingesta óptima de proteínas para alcanzar el máximo desarrollo muscular se sitúa en 3, 3-3,4 g de proteínas por kg de masa muscular ${ }^{3,54}$.

Por lo tanto, desde el punto de vista dietético-nutricional, es importante conocer cuáles son los objetivos del entrenamiento (si el trabajo prioritario que realizar es de resistencia aeróbica o fuerza) para poder realizar un asesoramiento preciso basado en las necesidades proteicas. Otra variable que considerar es el grado de daño tisular en la práctica de un determinado deporte, ya que en un trabajo muscular excéntrico, aun siendo prioritariamente de resistencia aeróbica, al ser más traumático, la ingesta proteica debería aumentar como si se tratase de un entrenamiento de fuerza ${ }^{28,29}$.

\section{Suplementos proteicos}

Si bien es cierto que varios estudios señalan que los deportistas pueden necesitar un mayor aporte proteico que los individuos sedentarios, también recomiendan que estas proteínas adicionales procedan de alimentos en estado natural, en lugar de suplementos $33,47,60,61$.

En los últimos años ha aumentado mucho el consumo de suplementos dietéticos relacionados con proteínas y AA específicos. Desde el punto de vista dietético-nutricional es importante tener en cuenta que la ingesta proteica de fuentes alimentarias de calidad puede ser mejor que la ingesta de $A A$ aislados para conseguir el mantenimiento o el aumento muscular ${ }^{62}$. Así, en los estudios de Weideman (1990) ${ }^{62}$ y Lemon (1996) ${ }^{44}$, se demostró que la administración de 2,94 g y 1,85-2,62 g de proteínas/ kg de peso corporal al día, respectivamente, mediante suplementación proteica rica en AA específicos, no incrementó la fuerza de los atletas.

Los hidrolizados de proteínas pueden ser de gran utilidad para favorecer su absorción ${ }^{63}$ y los procesos de regeneración muscular ${ }^{42,64}$, ya que muestran ser más eficaces en comparación con la toma de AA esenciales ${ }^{65}$. Sin embargo, si no hay un déficit en la dieta habitual que justifique su toma y no se mantiene una ingesta energéticamente positiva (200$500 \mathrm{kcal} /$ día, superior a las necesidades energéticas), no resultan ser $\tan$ eficaces ${ }^{51,60,66}$

La suplementación con AA ramificados es aún controvertida. Parece ser que estos pueden tener un papel como medida preventiva, reduciendo el índice de degradación de proteínas endógenas durante el ejercicio y ayudando a mantener una adecuada relación entre el triptófano y los AA ramificados ${ }^{67}$; no obstante, no está demostrado que, al tomarlos, aumente el rendimiento deportivo durante la competición ${ }^{51}$.

Según los estudios realizados por Blomstrand et al ${ }^{67}$ (1991), con una muestra de 193 corredores de maratón, en los atletas más lentos (maratón entre 3.05 y 3.30 horas) la suplementación con AA ramificados producía un efecto beneficioso, hecho que no se observó en corredores más rápidos (maratón de menos de 3 horas), probablemente debido a que agotaban antes los depósitos de glucógeno muscular, lo que producía un descenso más rápido de AA ramificados en sangre.

También es controvertido el uso de la leucina. Algunos estudios concluyen que existe un aumento de la síntesis 
proteica tras el ejercicio, tanto en jóvenes como en ancianos, utilizando la leucina como suplemento68.70. Sin embargo, en otros trabaj os realizados en varones de edad avanzada, no se ha observado el mismo efecto ${ }^{56,57}$.

En las últimas investigaciones realizadas respecto a la utilidad de AA ramificados, como la leucina en el deporte, parece que esta podría ayudar en la mejora de la recuperación muscular, ya que se observa una disminución de los parámetros de destrucción muscular como la creatincinasa (CK) y la lactato deshidrogenasa (LDH) ${ }^{71}$. En este sentido, parece ser que la suplementación con ciertos AA estaría más justificada después del ejercicio ${ }^{72}$.

Sólo unos pocos suplementos han demostrado amplia y claramente que pueden tener propiedades ergonutricionales; uno de ellos es la creatina ${ }^{73,74}$, AA que se sintetiza en el riñón y el hígado mediante la glicina y la arginina. La creatina debe indicarse en deportes con un componente explosivo, donde existe una gran intensidad en un corto espacio de tiempo, así como en los entrenamientos de hipertrofia muscular ${ }^{74}$. En deportes de resistencia aeróbica, puede tener un efecto perjudicial debido a una mayor retención de líquidos, lo que genera un aumento del peso total sin aportar un beneficio añadido al rendimiento.

\section{Estrategias dietético-nutricionales para el aumento de la masa muscular}

El tejido muscular está compuesto por un $70 \%$ de agua y un $22 \%$ de proteínas, el porcentaje restante corresponde a las reservas de grasa, glucógeno y minerales. Debido a su gran contenido en agua, el valor calórico total del tej ido muscular es de tan sólo 1.400-1.600 kcal por kilo de músculo. Un aumento en la masa muscular viene acompañada siempre de un incremento del agua corporal total, y es necesaria una cantidad adicional de energía, así como un balance nitrogenado positivo, para poder sintetizar más tej ido muscu$\operatorname{lar}^{75}$.

En este sentido, por una parte, la Sociedad Internacional de Nutrición Deportiva recomienda tomar entre 1,4 y $2 \mathrm{~g}$ de proteínas por $\mathrm{kg}$ de peso corporal/ día, según el tipo de esfuerzo físico realizado, la etapa de la vida, el estado fisiológico, el sexo y la composición corporal ${ }^{76}$. Sin embargo, como se ha comentado en apartados anteriores, en general se ha consensuado que los deportistas que necesiten aumentar la masa muscular deben realizar una ingesta proteica de 1,6-1,8 g/ kg de peso corporal ${ }^{3,44}$. Estas cantidades se pueden obtener mediante una dieta bien planificada y equilibrada, pero en el caso de atletas que entrenan varias veces al día y les sea muy complicado obtener los alimentos adecuados, estarían indicados los suplementos proteicos y de $\mathrm{HC}^{77}$.

Por otra parte, el National Research Cuncil (NRC) señala que los niños durante la etapa de crecimiento necesitan $5 \mathrm{kcal}$ para aumentar $1 \mathrm{~g}$ de tejido muscular, y otros autores, como Forbes y Powers ${ }^{38}$ (1994), estiman que los adultos requieren $8 \mathrm{kcal}$ para aumentar $1 \mathrm{~g}$ de tej ido muscular. Así, un margen adicional de 2.300-3.500 calorías por semana (un extra de $329-500 \mathrm{kcal} /$ día) puede ser una cantidad adecuada para promover la síntesis proteica y conseguir un aumento muscular, siempre y cuando se combine adecuadamente con un ejercicio físico específico de fuerza máxima hipertrófica ${ }^{78}$. Bartels et $\mathrm{al}^{34}$ (1992) señalan que un incremento adicional de $500 \mathrm{kcal} /$ día puede ayudar a aumentar en $0,5 \mathrm{~kg}$ de peso magro por semana durante un programa de entrenamiento de fuerza. Incluso en al gunos casos se aconseja un aumento del $15 \%$ de la energía necesaria al día para promover el aumento de masa muscular ${ }^{79,80}$. Por todo ello, es necesario personalizar las ingestas, ya que los deportistas con un gran desarrollo muscular (más de $50-52 \mathrm{~kg}$ de masa muscular), y especialmente si entrenan fuerza-resistencia, necesitan un aporte adicional de proteínas. En este sentido, una dieta con un balance positivo en energía, principalmente en forma de hidratos de carbono (60-70\%), puede mejora el equilibrio proteico y, en consecuencia, no sería necesario exceder las cantidades recomendadas de proteínas señaladas en los apartados anteriores (Davids, 1996; Devolve, 1997) ${ }^{81 ; 82}$. En la figura 2 se muestra un resumen de las consideraciones y los aspectos que tener en cuenta para la ganancia de masa muscular en el deportista.

El momento óptimo para el anabolismo proteico comienza tras el entrenamiento, durante las primeras 2 horas, y se prolonga hasta las siguientes 6 horas, ya que durante ese tiempo, además de verse aumentado el paso de glucosa en la célula muscular por un proceso independiente de la insulina, el recambio proteico también se ve aumentado ${ }^{36,83}$. En estas primeras 2 horas la ingesta de HC permite una resíntesis del glucógeno muscular ${ }^{35}$, debido a que aumentan los valores de insulina ${ }^{84,85}$, y los procesos anabólicos se dan con mayor eficacia y mejora el estado hormonal tras el ejerci$\mathrm{cio}^{3,14,49}$. Sin embargo, diversos estudios postulan un consumo de HC y proteínas antes y durante el entrenamiento para disminuir el catabolismo proteico y prescindir posteriormente de un suplemento de proteínas en las fases de recuperación ${ }^{86}$

En conclusión, para estimular la síntesis proteica y, por lo tanto, aumentar la masa muscular, es importante la cantidad y el tipo de HC, la ingesta de proteínas y el momento de su consumo. Aunque, en un principio, algunos estudios observaron que el envejecimiento podría afectar al recambio proteico tras el ejercicio ${ }^{55,87}$, trabajos posteriores demuestran que no hay diferencias significativas entre los deportistas jóvenes y los adultos ${ }^{42,48}$, siempre y cuando se tengan en cuenta las ingestas anteriormente citadas ${ }^{88}$.

En algunos trabajos realizados con deportistas que practican fitness o culturismo, cuyo objetivo principal es aumentar su masa muscular, se describe que la ingesta proteica espontánea de origen alimentario se situaba por encima de los val ores anteriormente comentados, lo que indica que la toma de suplementos de proteínas no supondría una ventaja adicional 78,88

En cuanto a la calidad de la fuente proteica, cabe destacar que, aunque las de origen animal suelen ser las más completas y de mejor valor biológico, las de origen vegetal pueden of recer la misma calidad o incluso superior siempre y cuando se acompañen de manera adecuada con diferentes grupos alimentarios, como es el caso de las legumbres con los cereales ${ }^{40,50,75}$, como podemos observar en la tabla 3.

Según las evidencias publicadas, tras el entrenamiento sería conveniente añadir alimentos ricos en $\mathrm{HC}$, junto con una pequeña cantidad de proteínas, para restablecer cuan- 


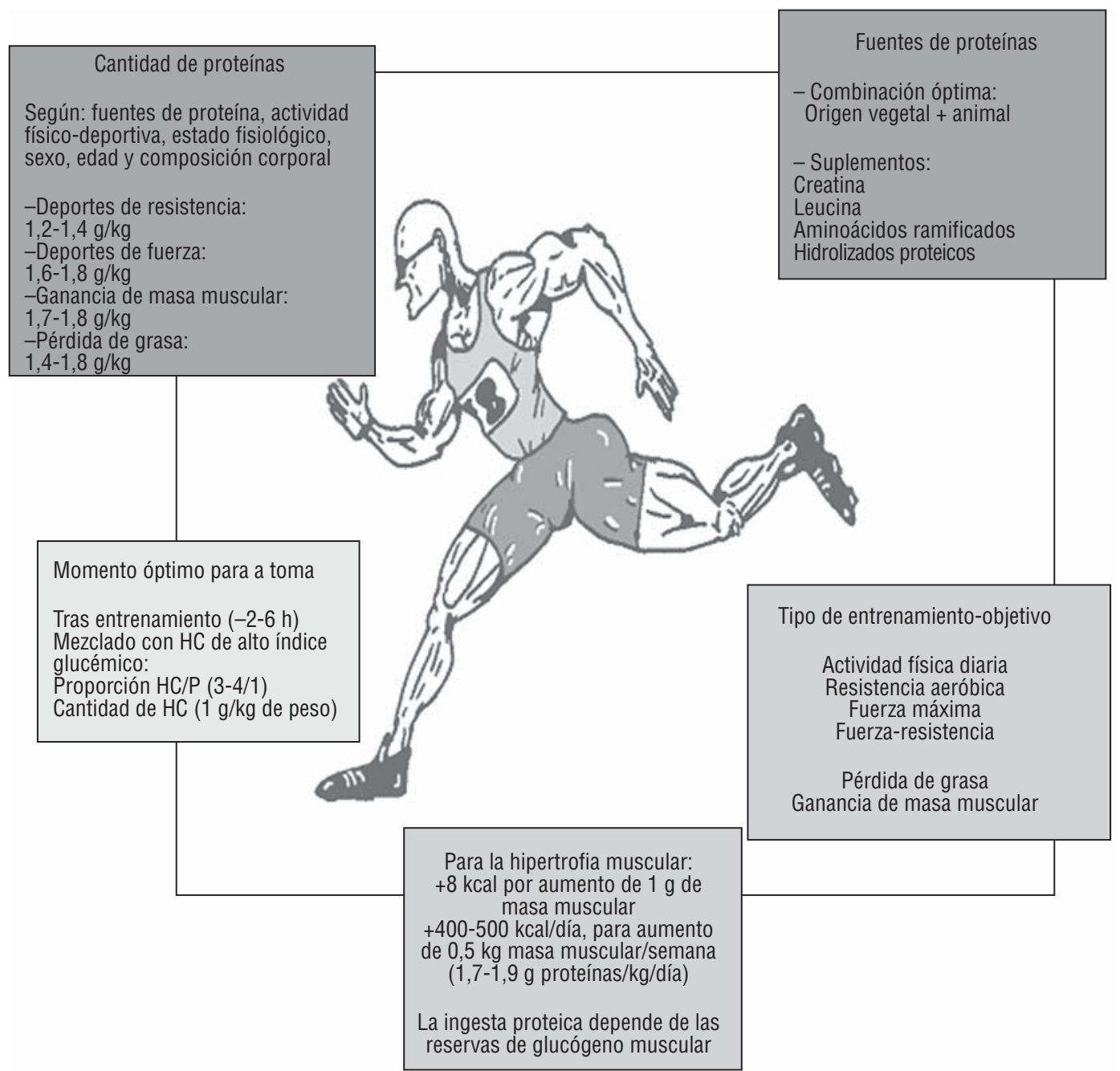

Figura 2 Características que influyen en la ganancia de masa muscular en el deportista. HC: hidratos de carbono; P: proteínas. Fuente: elaboración propia.

to antes el balance anabólico. Para unas rápidas digestión y asimilación de estos alimentos se debería consumirlos en forma de bebida, con una proporción de HC:proteínas de 4-3 g: $1 \mathrm{~g}^{25,30}$. Es importante indicar que dichos alimentos contengan azúcares simples o $\mathrm{HC}$ de alto índice glucémico con la finalidad de producir un máximo de insulina que ayude a restablecer los depósitos de glucógeno y facilitar la recuperación del deportista para continuar entrenando intensamente en sesiones posteriores. En este caso, una combinación de leche desnatada con zumo podría ser lo ideal. Los suplementos proteicos se recomendarían en los casos en que el individuo necesite ingerir la energía adicional inmediatamente tras el entrenamiento y no tenga a su alcance los alimentos anteriormente comentados.

\section{Discusión y conclusiones}

Según el documento de posicionamiento de la Asociación Americana de Dietética en $2009^{89}$, en deportes de resistencia, se puede establecer una ingesta de proteínas por encima de las recomendaciones diarias permitidas (RDA), junto con el suficiente aporte de energía (necesaria para el ejercicio de resistencia), para el correcto crecimiento muscu$\operatorname{lar}^{36}$. Este aumento es importante en la primera fase del entrenamiento de fuerza, ya que en ese momento se produce una ganancia muscular significativa. En estudios realizados con ancianos desentrenados, se ha observado que la ingesta de un suplemento proteico que suponía el $50 \%$ de la IR de proteínas, acompañado de un programa de entrenamiento de fuerza durante 3 meses, aumentaba el área muscular y la excreción de creatinina en la orina. Por otro lado, no se observaron aumentos significativos en la fuerza, pero este hecho no tiene por qué estar relacionado con el aumento de la hipertrofia muscular ${ }^{90,91}$. De todos modos, existen pocos estudios en relación con los requerimientos diarios de proteínas de los ancianos ${ }^{56,87,92} 0$ los niños y adolescentes ${ }^{55,86}$ que realizan ejercicio físico de forma regu$\operatorname{lar}^{38}$. La razón puede estar en la reciente incorporación de estos colectivos a programas de entrenamiento y, por consiguiente, sería interesante profundizar más en este campo.

En la mayoría de los casos las cantidades óptimas de proteínas pueden obtenerse con una dieta equilibrada, teniendo siempre en cuenta la calidad de estas (tabla 3), por lo 
Tabla 3 Calidad proteica de los alimentos de origen animal y vegetal

\begin{tabular}{|c|c|c|c|c|c|}
\hline & Digestibilidad & Valor biológico & $\begin{array}{l}\text { Utilización neta } \\
\text { proteica }\end{array}$ & AA limitantes & Exceso de AA \\
\hline \multicolumn{6}{|c|}{ Alimentos de origen animal } \\
\hline Carne & 97 & 75 & 73 & $\begin{array}{l}\text { Metionina } \\
\text { Triptófano }\end{array}$ & $\begin{array}{l}\text { Lisina } \\
\text { Treonina }\end{array}$ \\
\hline Huevos & 99 & 94 & 93 & & \\
\hline Leche & 98 & 84 & 81 & $\begin{array}{l}\text { Metionina } \\
\text { Histidina } \\
\text { Triptófano }\end{array}$ & $\begin{array}{l}\text { Treonina } \\
\text { Tirosina } \\
\text { Leucina } \\
\text { Valina } \\
\text { Lisina } \\
\text { Isoleucina }\end{array}$ \\
\hline Queso & 98 & 71 & 70 & $\begin{array}{l}\text { Metionina } \\
\text { Histidina } \\
\text { Triptófano }\end{array}$ & $\begin{array}{l}\text { Treonina } \\
\text { Tirosina } \\
\text { Leucina } \\
\text { Valina } \\
\text { Lisina }\end{array}$ \\
\hline \multicolumn{6}{|c|}{ Alimentos de origen vegetal } \\
\hline Legumbres & 83 & 85 & 71 & Metionina & Lisina \\
\hline Cereales refinados & 95 & 60 & 57 & Lisina & Metionina \\
\hline Cereales integrales & 85 & 65 & 55 & Lisina & Metionina \\
\hline
\end{tabular}

que no se necesitaría ningún tipo de suplemento. Los HC complejos como la patata, el arroz, la pasta o el pan son una buena fuente energética y también proteica si se combinan con otros alimentos como legumbres o leche. El exceso en la ingesta de algunos AA puede interferir en la absorción de los que se encuentran en menor cantidad, ya que existe una competencia entre ellos ${ }^{67}$. Por lo tanto, la ingesta de un suplemento que contenga un solo AA podría ocasionar una disminución de la síntesis proteica e incluso posibilitar el déficit de algún AA esencial.

Según el gasto y el aporte energético de un deportista, el aporte de las proteínas se calcula sobre la base de la cantidad proteica necesaria por cada $\mathrm{kg}$ de peso corporal de cada individuo en concreto ${ }^{93}$ y según su disciplina deportiva (tabla 1). Es importante que los depósitos de glucógeno muscular y hepático no permanezcan vacíos porque de lo contrario las necesidades proteicas aumentarían para mantener la masa muscular. El hecho de que el ser humano no disponga de un tejido que permita grandes reservas de AA (como ocurre con la glucosa en forma de glucógeno y ácidos grasos (AG) en forma de triglicéridos), produce que un exceso de proteínas ( $>2 \mathrm{~g} / \mathrm{kg} /$ día) pueda dar lugar, mediante procesos de desaminación y transaminación, a un aumento del peso corporal en forma de masa grasa. Este exceso puede conducir, además, a la deshidratación precoz por el aumento de cuerpos cetónicos y de urea en sangre.

Los estudios publicados sobre la ingesta de proteínas o suplementos de AA y sus efectos en la masa muscular y la fuerza ${ }^{94}$ deberían considerar también otras variables importantes, como hormonas, testosterona, cortisol e insulina, para mantener las condiciones experimentales lo más homogéneas posibles. Desde el punto de vista de la fisiología nutricional, los estudios deberían aportar información so- bre el momento de la toma del suplemento, calidad de la proteína que se consume habitualmente en la dieta y la cantidad de HC diaria, ya que estos aspectos pueden ser determinantes para el aumento de la masa muscular ${ }^{72,95,96}$. Además, se debe tener en cuenta que no se ha demostrado de manera positiva que las proteínas o los suplementos de AA tengan influencia en el rendimiento deportivo, y estas recomendaciones de suplementación deben dirigirse principalmente a la optimización de la respuesta a la formación y el periodo de recuperación después del ejercicio ${ }^{89}$. En este sentido, resulta prioritario para el organismo recuperar la pérdida intramuscular de AA y glucógeno tras el entrenamiento y/ o la competición ${ }^{97}$.

Como resumen y para dar un enfoque práctico podríamos decir que:

1. Las necesidades proteicas dependen de la cantidad del glucógeno muscular del deportista, es decir de cómo esté entrenando, con reservas de glucógeno reducidos o con reservas altas. En esto podemos intervenir con una dieta alta en $\mathrm{HC}$ y así tener necesidades menores de proteínas y menos gasto en una posible suplementación.

2. En la dieta habitual podemos obtener suficiente cantidad de proteínas y de gran valor biológico (proteína del huevo o leche) que, a la vez, pueden absorberse rápidamente; en el caso de la leche, si es desnatada, es más fácil. No obstante, si no se llega a las necesidades, lo mejor es tomar un suplemento de proteínas hidrolizadas y no de AA específicos. En caso de proteínas concretas, las de suero se absorben más rápidamente y la caseína, más lentamente.

3. Después de la competición, es importante hacer una mezcla de HC/P en una proporción de 3-4/1, porque la 
absorción de los macronutrientes en las primeras 6 horas es más rápida y porque está demostrado que añadir cierta cantidad de proteínas a los HC después del deporte ayuda a recuperar más rápidamente los depósitos de glucógeno muscular. Podemos conseguir esta proporción mediante suplementos deportivos (mezcla de HC y proteínas), pero también con alimentos que utilizamos diariamente, por ejemplo, mezclar zumo con leche desnatada hasta conseguir la proporción ideal.

\section{Conflicto de intereses}

El presente artículo no presenta conflictos de intereses de tipo económico con instituciones, organizaciones o autores.

\section{Bibliografía}

1. Wolfe R, George S. Stable isotopic tracers as metabolic probes in exercise. Exercise and Sport Sciences Reviews. 1993;21:131.

2. Reeds $P$, Hutchens T. Protein requirements: From nitrogen balance to functional inpact. J Nutr. 1994:124:1754-64.

3. Burd NA, Tang JE, Moore DR, Phillips SM. Exercise training and protein metabolism: influences of contraction, protein intake, and sex-based differences. J Appl Physiol. 2009; 106:1692-701.

4. Lemon P. Protein requirements and muscle mass/strength changes during intensive training in nocive bodybuilders. J Appl Physiol. 1992; 73:767-75.

5. Poortmans J. Protein metabolism. En: Principles of Exercise Biochemistry. Basel: Karger; 1993.

6. Kleiner S. The role of meat in athete's diet. Sports Science Exchange. 1995; 8:1-6.

7. Rasmussen BB, Phillips SM. Contractile and nutritional regulation of human muscle growth. Exerc Sport Sci Rev. 2003;31:12731.

8. Morifuji M, Kanda A, Koga J, Kawanaka K, Higuchi M. Post-exercise carbohydrate plus whey protein hydrolysates supplementation increases skeletal muscle glycogen level in rats. Amino Acids. 2010;38: 1109-15.

9. Tipton KD, Rasmussen BB, Miller SL, Wolf SE, Owens-Stovall SK, Petrini $B E$, et al. Timing of amino acid-carbohydrate ingestion alters anabolic response of muscle to resistance exercise. Am J Physiol Endocrinol Metab. 2001;281:197-206.

10. Buse MG, Reid SS. Leucine. A possible regulator of protein turnover in muscle. J Clin Invest. 1975;56:1250-61.

11. Fitts R, Widrick J. Muscle mechaniscs: adaptations with exercise-training. Exercise and Sports Sciences Reviews. 1996;24:42773.

12. Parkhouse W. Regulation of skeletal muscle myofibrillar protein degradation: Relationship to fatigue and exercise. International J ournal of Biochemistry. 1988;20:769-75.

13. Tipton KD, Elliott TA, Ferrando AA, Aarsland AA, Wolfe RR. Stimulation of muscle anabolism by resistance exercise and ingestion of leucine plus protein. Appl Physiol Nutr Metab. 2009;34:151-61.

14. Hulmi JJ, Kovanen V, Selänne $H$, Kraemer WJ, Häkkinen $K$, Mero AA. Acute and long-term effects of resistance exercise with or without protein ingestion on muscle hypertrophy and gene expression. Amino Acids. 2009;37:297-308.

15. Hulmi JJ, Volek JS, Selänne H, Mero AA. Protein ingestion prior to strength exercise affects blood hormones and metabolism. Med Sci Sports Exerc. 2005;37:1990-7.
16. Willoughby DS, Stout J R, Wilborn CD. Effects of resistance training and protein plus amino acid supplementation on muscle anabolism, mass, and strength. Amino Acids. 2007; 32:467-77.

17. Mäestu J, Eliakim A, J ürimäe J, Valter I, J ürimäe T. Anabolic and catabolic hormones and energy balance of the male bodybuilders during the preparation for the competition. J Strength Cond Res. 2010;24:1074-81.

18. Paddon-J ones D, Sheffield-Moore M, Katsanos CS, Zhang XJ, Wolfe RR. Differential stimulation of muscle protein synthesis in elderly humans following isocaloric ingestion of amino acids or whey protein. Exp Gerontol. 2006;41:215-9.

19. Symons TB, Sheffield-Moore M, Wolfe RR, Paddon-J ones D. A moderate serving of high-quality protein maximally stimulates skeletal muscle protein synthesis in young and elderly subjects. J Am Diet Assoc. 2009; 109: 1582-6.

20. Thalacker-Mercer AE, Fleet J C, Craig BA, Carnell NS, Campbell WW. Inadequate protein intake affects skeletal muscle transcript profiles in older humans. Am J Clin Nutr. 2007; 85:1344-52.

21. Andersen LL, Tufekovic G, Zebis MK, Crameri RM, Verlaan G, Kjaer $M$, et al. The effect of resistance training combined with timed ingestion of protein on muscle fiber size and muscle strength. Metabolism. 2005; 54:151-6.

22. Blomstrand E, Eliasson J, Karlsson HK, Kohnke R. Branchedchain amino acids activate key enzymes in protein synthesis after physical exercise. J Nutr. 2006; 136:269-73.

23. Nolles JA, Verreijen AM, Koopmanschap RE, Verstegen MW, Schreurs VV. Postprandial oxidative losses of free and proteinbound amino acids in the diet: interactions and adaptation. J Anim Physiol Anim Nutr. 2008; 3:320-31.

24. Ratamess NA, Kraemer WJ, Volek JS, Rubin MR, Gomez AL, French DN, et al. The effects of amino acid supplementation on muscular performance during resistance training overreaching. J Strength Cond Res. 2003; 17:250-8.

25. Berardi J M, Noreen EE, Lemon P. Recovery from a cycling time trial is enhanced with carbohydrate-protein supplementation vs. isoenergetic carbohydrate supplementation. J Int Soc Sports Nutr. 2008;24:5-24.

26. Bird SP, Tarpenning KM, Marino FE. Liquid carbohydrate/ essential amino acid ingestion during a short-term bout of resistance exercise suppresses myofibrillar protein degradation. Metabolism. 2006; 55:570-7.

27. Etheridge T, Philp A, Watt PW. A single protein meal increases recovery of muscle function following an acute eccentric exercise bout. Appl Physiol Nutr Metab. 2008;33:483-8.

28. Buckley JD, Thomson RL, Coates AM, Howe PR, DeNichilo MO, Rowney MK. Supplementation with a whey protein hydrolysate enhances recovery of muscle force-generating capacity following eccentric exercise. J Sci Med Sport. 2010;13:178-81.

29. Hoffman JR, Ratamess NA, Tranchina CP, Rashti SL, Kang J, Faigenbaum AD. Effect of a proprietary protein supplement on recovery indices following resistance exercise in strength/ power athletes. Amino Acids. 2010;38:771-8.

30. Kreider RB, Earnest CP, Lundberg J, Rasmussen C, Greenwood $M$, Cowan $P$, el al. Effects of ingesting protein with various forms of carbohydrate following resistance-exercise on substrate availability and markers of anabolism, catabolism, and immunity. J Int Soc Sports Nutr. 2007; 12:4-18.

31. McCleave EL, Ferguson-Stegall L, Ding Z, Doerner P, Wang B, Kammer $L$, et al. Effect of a low carbohydrate-moderate protein supplement on endurance performance in female athletes. International J ournal of Exercise Science: Conference Abstract Submissions. 2010;2:345-56.

32. Ferguson-Stegall L, McCleave EL, Ding Z, Kammer LM, Wang B, Doerner PG, et al. The effect of a low carbohydrate beverage with added protein on cycling endurance performance in trained athletes. Journal of Strength \& Conditioning Research. 2010;24:2577-86. 
33. Kerksick C, Harvey T, Stout J, Campbell B, Wilborn C, Kreider $R$, et al. International Society of Sports Nutrition position stand: Nutrient timing. J Int Soc Sports Nutr. 2008;5-17.

34. Bartels R. Weight training. How to lift and eat for strength and power. Phys Sportsmed. 1992;20:223-34.

35. Biolo G, Maggi SP, Williams BD, Tipton KD, Wolfe RR. Increased rates of muscle protein turnover and amino acid transport after resistance exercise in humans. Am J Physiol. 1995;268:514-20.

36. Chesley A. Changes in human muscle protein synthesis after resistance exercise. J ournal of Applied Physiology. 1992; 73: 13838.

37. Etzel MR. Manufacture and use of dairy protein fractions. J Nutr. 2004;134: 996-1002.

38. Forbes DJ, Powers M. Cytosolic factors in nuclear transport: what's importin? Cell. 1994; 79:931-4.

39. Grandjean $A$, et al. What are the protein requeriments of athletes? Food and Nutrition News. 1993;65:11.

40. Hernandez M. The protein efficiency ratios of 30:70 mixtures of animal: Vegetable protein are similar or higher than those of the animal foods alone. I of Nutrition. 1996; 126:574-81.

41. Hicskson J, Wolinsky I. Research directions in protein nutrition for athletes. In Nutrition in Exercise Sports. Boca Ratón: CRC Press; 1994.

42. Koopman R, Walrand S, Beelen M, Gij sen AP, Kies AK, Boirie $Y$, et al. Dietary protein digestion and absorption rates and the subsequent postprandial muscle protein synthetic response do not differ between young and elderly men. J Nutr. 2009; 139: 1707-13.

43. Lemon P. Beyond the zone: protein needs of active individuals. Am Coll Nutr. 2000;19:513-21.

44. Lemon P. Is increased dietary protein necessary or beneficial for individuals with a physically active lifestyle? Nutrition Reviews. 1996; 54: 169-75.

45. Mettler S, Mitchell N, Tipton KD. Increased protein intake reduces lean body mass loss during weight loss in athletes. Med Sci Sports Exerc. 2010;42:326-37.

46. Nemet D, Wolach B, Eliakim A. Proteins and amino acids supplementation in sports: are they truly necessary? Isr Med Assoc J. 2005; 7:328-32.

47. Paul G. Dietary protein requirements of physically active individuals. Sports Medicine. 1989;8:154-76.

48. Symons TB, Schutzler SE, Cocke TL, Chinkes DL, Wolfe RR, Paddon-J ones D. Aging does not impair the anabolic response to a protein-rich meal. Am J Clin Nutr. 2007;86:451-6.

49. Tipton KD, Elliott TA, Cree MG, Aarsland AA, Sanford AP, Wolfe RR. Stimulation of net muscle protein synthesis by whey protein ingestion before and after exercise. Am J Physiol Endocrinol Metab. 2007;292:71-6.

50. Urdampilleta A, Martínez-Sanz J M. La dieta vegetariana: Limitaciones y sus posibles efectos en el rendimiento físico-deportivo. Lecturas: Educación Física y Deportes. Año 15, n. ${ }^{\circ}$ 150, Noviembre, 2010. Revista digital. Disponible en: http:// www. efdeportes.com

51. Willians M. Nutritional supplements for strength trained athletes. Sports Science Exchange. 1993;6:1-6.

52. Lesourd B. Protein undernutrition as the major cause of decreased immune function in the elderly: clinical and functional implications. Nutrition Reviews. 1995;53:86-94.

53. Krissansen GW. Emerging health properties of whey proteins and their clinical implications. J Am Coll Nutr. 2007;26:713-23.

54. Hoffman JR, Ratamess NA, Tranchina CP, Rashti SL, Kang J, Faigenbaum AD. Effect of protein-supplement timing on strength, power, and bodycomposition changes in resistance-trained men. Int J Sport Nutr Exerc Metab. 2009; 19:172-85.

55. Dangin M, Boirie $Y$, Guillet C, Beaufrere B. Influence of the protein digestion rate on protein turnover in young and elderly subjects. J Nutr. 2002;132:3228-33.
56. Koopman R, Verdijk LB, Beelen M, Gorselink M, Kruseman AN, Wagenmakers $\mathrm{A} J$, et al. Co-ingestion of leucine with protein does not further augment post-exercise muscle protein synthesis rates in elderly men. Br J Nutr. 2009; 99:571-80.

57. Verhoeven S, Vanschoonbeek K, Verdijk LB, Koopman R, Wodzig WK, Dendale $P$, et al. Long-term leucine supplementation does not increase muscle mass or strength in healthy elderly men. Am J Clin Nutr. 2009; 89: 1468-75.

58. Verdijk LB, J onkers RA, Gleeson BG, Beelen M, Meijer K, SaveIberg $\mathrm{HH}$, et al. Protein supplementation before and after exercise does not further augment skeletal muscle hypertrophy after resistance training in elderly men. Am J Clin Nutr. 2009; 89:608-16

59. Alvero Cruz JR, Cabañas MD, Herrero A, Martinez L, Moreno C, Porta J, et al. Protocolo de valoración de la composición corporal para el reconocimiento médico-deportivo. Archivos de Medicina del Deporte. 2010;131:166-79.

60. Elliot TA, Cree MG, Sanford AP, Wolfe RR, Tipton KD. Milk ingestion stimulates net muscle protein synthesis following resistance exercise. Med Sci Sports Exerc. 2006;38:667-74.

61. Phillips SM, Tang JE, Moore DR. The role of milk- and soy-based protein in support of muscle protein synthesis and muscle protein accretion in young and elderly persons. J Am Coll Nutr. 2009;28:343-54.

62. Weideman $\mathrm{C}$ el al. Effects of increased protein intake on muscle hypertrophy and strength following 13 weeks of resistance training. Med Sci Sports Exerc. 1990;22:37-9.

63. Manninen AH. Protein hydrolysates in sports nutrition. Nutr Metab (Lond). 2009;6:38.

64. Calbet J A, Holst JJ. Gastric emptying, gastric secretion and enterogastrone response after administration of milk proteins or their peptide hydrolysates in humans. EurJ Nutr. 2004;43:12739.

65. Katsanos CS, Chinkes DL, Paddon-J ones D, Zhang XJ, Aarsland A, Wolfe RR. Whey protein ingestion in elderly persons results in greater muscle protein accrual than ingestion of its constituent essential amino acid content. Nutr Res. 2008;28:651-8.

66. Fouillet H, Gaudichon C, Mariotti F, Bos C, Huneau J F, Tome D. Energy nutrients modulate the splanchnic sequestration of dietary nitrogen in humans: a compartmental analysis. Am J Physiol Endocrinol Metab. 2001;281:248-60.

67. Blomstrand E, Saltin B. BCAA intake affects protein metabolism in muscle after but not during exercise in humans. Am J Endocinol Metab. 2001;281:365-74.

68. Katsanos CS, Kobayashi H, Sheffield-Moore M, Aarsland A, Wolfe RR. A high proportion of leucine is required for optimal stimulation of the rate of muscle protein synthesis by essential amino acids in the elderly. Am J Physiol Endocrinol Metab. 2006;291:381-7.

69. Koopman R, Wagenmakers AJ, Manders RJ, Zorenc AH, Senden J , Gorselink M, et al. Combined ingestion of protein and free leucine with carbohydrate increases postexercise muscle protein synthesis in vivo in male subjects. Am J Physiol Endocrinol Metab. 2005; 288:645-53.

70. Rieu I, Balage M, Sornet C, Debras E, Ripes S, Rochon-Bonhomme $C$, et al. Increased availability of leucine with leucine-rich whey proteins improves postprandial muscle protein synthesis in aging rats. Nutrition. 2007;23:323-31.

71. Kraemer WJ, Hatfield DL, Volec JS, Fragala MS, Vingren J L, Anderson J M, et al. Effects of amino acids supplement on physiological adaptations to resistance training. Med Sci Sports Exerc. 2009; 4:1111-21.

72. Stock MS, Young J C, Golding LA, Kruskall LI, Tandy RD, ConwayKlaass J M, et al. The effects of adding leucine to pre and postexercise carbohydrate beverages on acute muscle recovery from resistance training. Strength Cond Res. 2010;24: 2211-9. 
73. Burke DG, Candow DG, Chilibeck PD, MacNeil LG, Roy BD, Tarnopolsky MA, et al. Effect of creatine supplementation and resistance-exercise training on muscle insulin-like growth factor in young adults. Int J Sport Nutr Exerc Metab. 2008;18:389-98.

74. Cribb PJ, Williams AD, Stathis CG, Carey MF, Hayes A. Effects of whey isolate, creatine, and resistance training on muscle hypertrophy. Med Sci Sports Exerc. 2007; 39:298-307.

75. Yalcin AS. Emerging therapeutic potential of whey proteins and peptides. Curr Pharm Des. 2006; 12:1637-43.

76. Campbell B, Kreider RB, Ziegenfuss T, La Bounty P, Roberts M, Burke $D$, et al. International Society of Sports Nutrition position stand: protein and exercise. J Int Soc Sports Nutr. 2007;26:4-8.

77. Kreider RB, Campbell B. Protein for exercise and recovery. Phys Sportsmed. 2009; 37:13-21.

78. Kimball SR. The role of nutrition in stimulating muscle protein accretion at the molecular level. Biochem Soc Trans. 2007; 35: 1298-301.

79. Tarnopolsky M. Protein requirements for endurance athletes. Nutrition. 2004;20:662-8.

80. Lambert CP, Frank LL, Evans WJ . Macronutrient considerations for the sport of bodybuilding. Sports Med. 2004;34:317-27.

81. Davis J M. Carbohydrates, branched-chain amino acids and endurance: The central fatigue hypothesis. Sports Science Exchange. 1996; 9:1-5.

82. Devolve K. Effects of carbohydrate and branch-chain amino acid ingestion on intermittent, hight intensity running. Med Sci Sports Exerc. 1997;29:125.

83. Atherton PJ, Smith K, Etheridge T, Rankin D, Rennie MJ. Distinct anabolic signalling responses to amino acids in C2C12 skeletal muscle cells. Amino Acids. 2010;38:1533-9.

84. Tang JE, Manolakos JJ, Kuj bida GW, Lysecki PJ, Moore DR, PhiIlips SM. Minimal whey protein with carbohydrate stimulates muscle protein synthesis following resistance exercise in trained young men. Appl Physiol Nutr Metab. 2007;32:1132-8.

85. Kalman D, Feldman S, Martinez M, Krieger DR, Tallon MJ . Effect of protein source and resistance training on body composition and sex hormones. J Int Soc Sports Nutr. 2007;4:4.

86. Beelen M, Tieland M, Gij sen AP, Vandereyt $H$, Kies AK, Kuipers $\mathrm{H}$, et al. Coingestion of carbohydrate and protein hydrolysate stimulates muscle protein synthesis during exercise in young men, with no further increase during subsequent overnight recovery. J Nutr. 2008; 138:2198-204.

87. Dangin M, Guillet C, Garcia-Rodenas C, Gachon P, BouteloupDemange $C$, Reiffers-Magnani $K$, et al. The rate of protein digestion affects protein gain differently during aging in humans. J Physiol. 2003; 549:635-44.

88. Keith R. Nutritional status and lipid profiles of trained steroidusing bodybuilders. Int J Sports Nutr. 1996;6:247-54.

89. Position of the American Dietetic Association, Dietitians of Canada, and the American College of Sports Medicine: Nutrition and Athletic Performance. J Am Diet Assoc. 2009;109: 509-27.

90. Dillon EL, Sheffield-Moore M, Paddon-J ones D, Gilkison C, Sanford AP, Casperson SL, et al. Amino acid supplementation increases lean body mass, basal muscle protein synthesis, and insulin-like growth factor-I expression in older women. J Clin Endocrinol Metab. 2009;94:1630-7.

91. Onambélé-Pearson GL, Breen L, Stewart CE. Influences of carbohydrate plus amino acid supplementation on differing exercise intensity adaptations in older persons: skeletal muscle and endocrine responses. Age (Dordr). 2010;32:125-38.

92. Genaro PS, Martini LA. Effect of protein intake on bone and muscle mass in the elderly. Nutr Rev. 2010;68:616-23.

93. Wagenmarkers AJ M. Muscle amino acid metabolism at rest and during exercise in human physiology and metabolism. Exercise and Sport Sciences Reviews. 1998;26:287-314.

94. Racette SB. Creatine supplementation and atletic performance. J Orthop Sports Phys Ther. 2003;33:615-21.

95. Moore DR, Robinson MJ, Fry JL, Tang JE, Glover El, Wilkinson $\mathrm{SB}$, et al. Ingested protein dose response of muscle and albumin protein synthesis after resistance exercise in young men. Am J Clin Nutr. 2009;89:161-8.

96. Stearns RL, Emmanuel H, Volek J S, Casa DJ. Effects of ingesting protein in combination with carbohydrate during exercise on endurance performance: a systematic review with metaanalysis. J Strength Cond Res. 2010;24:2192-202.

97. Pérez-Guisado J. Rendimiento deportivo: glucógeno muscular y consumo protéico. Apunt Medicina del'Esport. 2008; 159: 142-52. 